\title{
Traditions, beliefs and indigenous technologies in connection with the edible longhorn grasshopper Ruspolia differens (Serville 1838) in Tanzania
}

\author{
Mercy W. Mmari ${ }^{i^{*}}$, John N. Kinyuru', Henry S. Laswai ${ }^{2}$ and Judith K. Okoth ${ }^{1}$
}

\begin{abstract}
Background: Edible insects are an important source of food to many African populations. The longhorn grasshopper, Ruspolia differens (Serville 1838), commonly known as senene in Tanzania is one of the most appreciated edible insects by societies around Lake Victoria crescent. Senene is primarily an essential treat for the tribes around the lake, e.g., the Haya of Tanzania, Luo of Kenya and Baganda of Uganda. Despite its importance as a food item and appreciation as a delicacy, there are few studies dealing with culture, beliefs and indigenous technology in connection with the senene. The main objective of this study was to survey indigenous technologies, processing methods and traditions in relation to senene consumption among the Haya tribe in Kagera region of Tanzania.
\end{abstract}

Methods: Our ethnographic study was conducted through semi-structured interviews. A total of 51 locals, 26 females and 25 males aged 21 to 60 years were interviewed (with 3 female and 7 male key informants among them). Questions focused on cultures, beliefs and traditions towards senene consumption. Processing, preservation and shelf-life as well as nutritional knowledge were also investigated.

Results: Harvesting for household consumption was mainly done through wild collection. Traditionally made traps were mostly used for commercial harvesting. Deep frying was the most preferred processing method while smoking was the most preferred preservation method, with shelf-life of up to 12 months. Interesting traditions and taboos associated with senene consumption were identified, with men monopolising the insects as food by declaring the insects taboo for women and children. Deep fried senene in locally packed containers were mostly sold by street vendors, but also available from a variety of stores and supermarkets.

Conclusion: Beyond being just an important traditional delicacy, senene is becoming increasingly popular, providing opportunity for local businesses. Indigenous technologies for harvesting, processing and preserving senene exist, but must be improved to meet food processing standards, thereby promoting commercialization. This carries economic potential essential for improving incomes and livelihoods of women and smallholder farmers, improving household level food security.

Keywords: Senene, Edible insects, Indigenous processing, Tanzania, Ethno-entomology, Food, Grasshopper

\footnotetext{
* Correspondence: mmarimercy@gmail.com

'Department of Food Science and Technology, Jomo Kenyatta University of

Agriculture and Technology, P. O. Box 62000-00200, Nairobi, Kenya

Full list of author information is available at the end of the article
} 


\section{Background}

Anthropo-entomophagy is spreading globally [1]. Although not fully embraced by the majority of Western cultures, consumption of edible insects by humans (anthropo-entomophagy) has existed since ancient times $[2,3]$. In developed countries like Japan and Korea, the grasshopper, Oxya yezoensis [4], remains popular as an edible species and globally, Orthoptera like grasshoppers and katydids, e.g., Ruspolia differens [5], locusts like Locusta migratoria [6] and crickets [7] play a major role among the more than 2000 species currently considered edible [8].

The East African longhorn grasshopper ( $R$. differens) is a cone-headed species commonly known as senene in Swahili which belongs to the family Tettigoniidae, suborder Ensifera and order Orthoptera. It is easily confused with related species including Ruspolia lineosa, Ruspolia nitidula and Ruspolia dubia [9] who are also referred to as senene. $R$. differens has different local names and is known as senesene in Kenya [10], nsenene in Uganda [9] and nshokonono in Zambia [11]. The nomenclature of $R$. differens has been a subject of interest among entomologists since its first description by Serville in 1838 as cited in [12]. More than ten scientific names have been suggested since then [9, 13-15].

Senene has been widely harvested and consumed as a traditional snack in Zambia and regions around Lake Victoria crescent including Tanzania, Uganda, Kenya and Democratic Republic of Congo. In these areas, indigenous people customarily consider senene and other edible insects to be highly nutritious and believe they have specific medicinal properties. The culture of senene consumption is indigenous to the Haya tribe found in the Lake zone of Tanzania, where the offering of senene is seen as a sign of respect to the person it is served to. This culture has now spread throughout Tanzania where senene is commercially available and widely consumed by different tribes. Senene is reported to be nutritious consisting of $44 \%$ protein and with good ratios of essential amino acids $[10,11,16,17]$. It is known for its high fat content, with high composition of essential fatty acids, up to $16 \%$ of $\alpha$-linolenic acid [11]. Senene is also rich in vitamins and minerals with higher nutrients bioavailability compared to most plants; up to $2.12 \mathrm{mg} / \mathrm{g}$ vitamin $\mathrm{A}, 0.99 \mathrm{mg} / 100 \mathrm{~g}$ folate, 2 to $16.6 \mathrm{mg} / 100 \mathrm{~g}$ iron and $17 \mathrm{mg} / 100 \mathrm{~g}$ zinc have been reported [5].

A few studies on $R$. differens from East Africa, mainly Uganda and Kenya, have reported data on trade and nutritional potential with fewer studies from Tanzania reporting on biology and phenology $[5,13,15]$. There are even fewer studies on culture, beliefs and indigenous technology associated with $R$. differens, despite the rising acceptance and prominence of this delicacy. It is crucial to understand indigenous technologies, culture and beliefs associated with consumption of $R$. differens for scaling up commercialization innovations as well as designing adoption for ongoing scientific findings.

\section{Methods \\ Study area}

The study was conducted in the northwestern corner of Tanzania in Kagera region, lying between $1^{\circ} 00^{\prime}$ and $2^{\circ} 45^{\prime} \mathrm{S}$ and $32^{\circ} 40^{\prime} \mathrm{E}$. The capital town of Kagera is Bukoba, which is about $1500 \mathrm{~km}$ from Dar es Salaam by road. Kagera region shares borders with Uganda to the North, Rwanda and Burundi to the West and Lake Victoria to the east. Main economic activities in this area include farming, fishing, livestock keeping and mining [18]. The natives of Kagera are mainly of Haya tribe for whom senene is an esteemed delicacy. This hilly terrain region with thick tropical vegetation including forests and wide-open grasslands experiences two rain seasons. The long rain season lasts from March to May, during which the study was conducted, while the short rain season lasts from October to December. The study focused on Muleba and Kagera urban districts where senene harvesting and enterprise is common.

\section{Sampling frame, sampling and interviews}

Twenty five males and 26 females randomly selected Haya adults from Muleba and Kagera urban districts of Kagera region were interviewed. Seven male and three female elders of Haya tribe and senene collectors were selected using snow ball sampling due to their distinct knowledge of local culture and senene. Senene collectors who were found at the senene collection points during the night were also interviewed. These experts were interviewed mainly to validate the findings and provide additional clarification around some of some beliefs and indigenous technologies outlined by interviewees. Information was collected through face to face interviews using questionnaires administered in Swahili. The study was of an ethnographic nature with interviews focused on perceptions, cultures and beliefs, indigenous technologies in harvesting, processing and preservation, and shelf-life as well as traditions towards senene consumption. Senene prices and nutrition knowledge among senene consumers were also collected through the questionnaires. In addition to the interviews, observations on harvesting, cooking and traditional processing of senene was carried out at the homestead, farms and wild fields. To document some of the traditional practices, photos of the insects, traditional traps and senene markets were taken. Samples of senene were collected from the fields and markets for identification and inventorying. 


\section{Data analysis}

Data were coded and entered in Statistical Package for Social Sciences (SPSS) version 21 where descriptive statistics were computed.

\section{Results and discussion}

Social-economic information of the respondents

Data was collected on socio-economic characteristics of respondents involved in the study including age, gender, tribe and occupation. The age of the respondents ranged from 21 to 60 years old with a majority (43\%) aged 21 to 30 years. Fifty one percent of respondents were female, these were first-hand informers as senene collection, and processing is dominated by women. Edible insect consumption is influenced by cultural belief system and differs across different ethnic groups, 90\% respondents were Hayas, other came from the Sukuma, Nyambo, Bunganda and Kerewe tribes. Interviewees' occupations were mainly local government officials (39\%) mostly from nature and forestry department, self-employed in informal sector including senene traders (33\%), peasant farmers (15\%) and students (13\%).

\section{Varieties and seasonality}

The respondents identified five culturally significant forms of senene, each carrying meaningful and unique Haya name (Fig. 1 a-e.). The names were based on the appearance and behaviour of each. Purple coloured senene were known as mwanamwana, which means 'beautiful woman' in Haya language. This was the rarest form of all. Kishorowanda is green with purple stripes. Mfaume is brown in colour, and it was said to be the most unpredictable, fierce, biting and hard to trap. Katikomile means dry tree in Haya language and was a brown-khaki senene; it was said to signify the end of the senene season. Kimbisimbisi was the name given to common green senene meaning 'green tree leaves', most abundant during the senene season. Studies on morphology report six colour forms which are said to be genetically controlled $[9,12]$. Some natives suggested that the
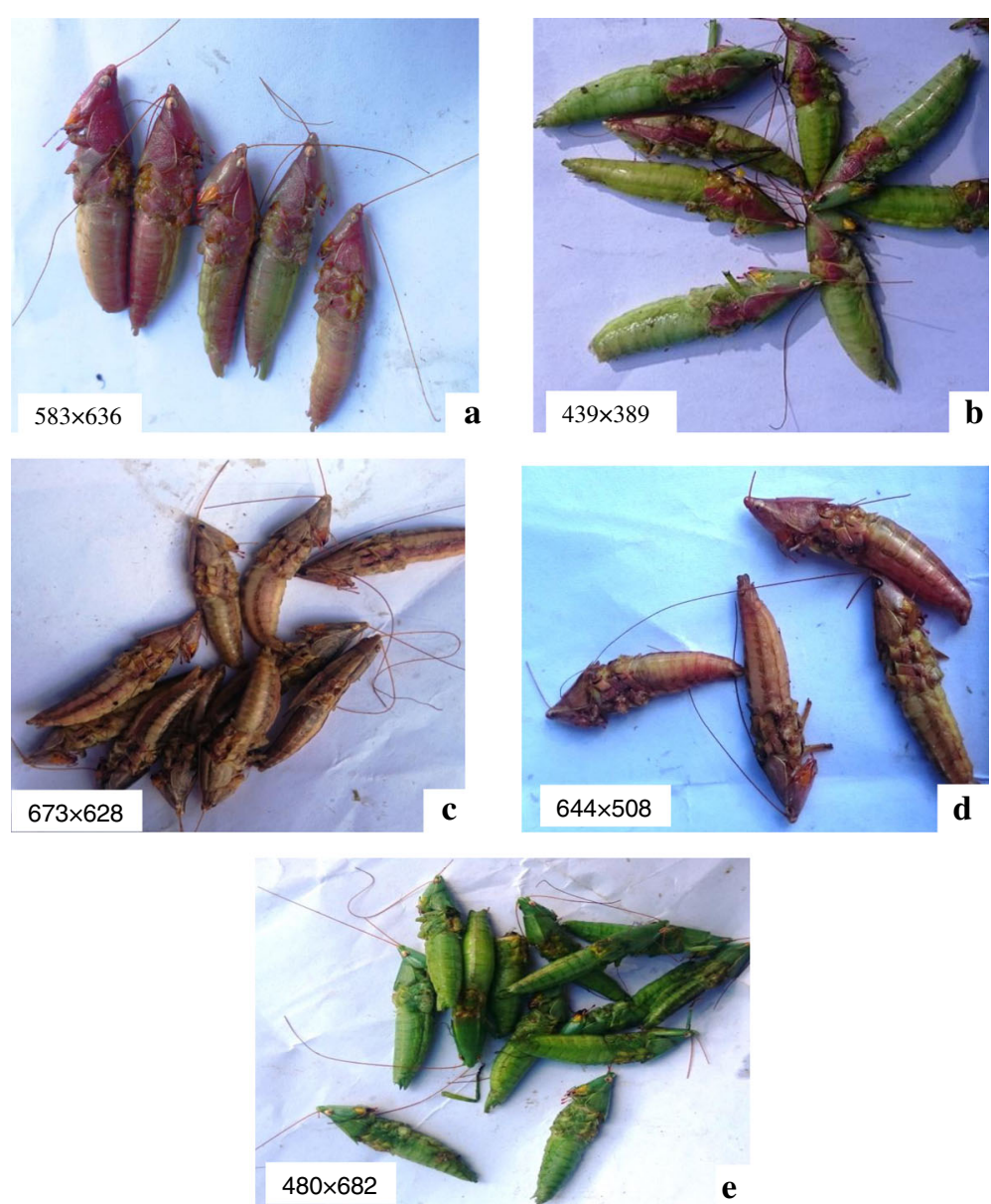

Fig. 1 a-e De-winged and de-legged senene varieties found in Kagera as identified by Haya ethnic group. a Mwanamwana meaning beautiful woman. b Mfaume meaning a ruler or confused person. c Kishorowanda meaning colourful bird. d Katikomile meaning dry tree. e Kimbisimbisi meaning greeny 
varieties taste different with, mwanamwana being reported as the tastiest. The green form was associated with femaleness and richness of the season while brown was said to mark the end of the season and was associated with maleness.

Senene swarms twice a year: April to June being the longest season and November to December being characterised by high numbers of senene. This season reaches its peak on around 9th in December, which is also an important national holiday in Tanzania known as Jamhuri day. It was believed that if someone could not succeed in collecting senene on this day, they are unlucky. Small black-brown flies known as Nairobi fly (Paederus eximius and Paederus sabaeus) accompanies senene, these tend to cause swellings on the faces and arms of the collectors a common challenge faced by senene collectors. 'Gathering senene is not an easy job as senene do come with soldiers' said one respondent who is also a senene collector when asked about the challenge he faces during collection. The feeling is mutual to senene collectors in Uganda as reported by Agea [13].

\section{Occurrence and availability}

When asked about the occurrence of senene, one old man aged 72 years explained that it is just God's plan for Kagera, I don't even understand because they just drop from heaven'. Most natives believe that senene came from heaven just like Manna dropped to Israelites in biblical times according to the Holy Bible in Exodus 16:1-36. It was further suggested that senene came from Lake Victoria; few believed that senene emerged from bushes and pine trees while others said they came from dense-dark clouds. According to Matojo and Yarro [19], bushes are the breeding grounds for $R$. differens, where both swarming and non-swarming adults lay eggs in ribbons cemented together. Time lapse between oviposition and maturity is reported to take about 3 months [14]. Senene swarms are reported to have decreased over time; some key informers' suggesting that climate change has significantly affected the current volumes of senene.

\section{Traditions, consumer perception, custom and taboos}

'Senene is an icon of Kagera, God's gift from heaven for Haya' as reported by one retired forest officer from Bukoba Municipal Council. It is a delicacy normally reserved for men and in-laws. Respondents listed different reasons for consumption; the most common of which include respect of traditional delicious delicacy (44\%) and source of nutrients (41\%) and tasty nature of senene as multipurpose sauce (15\%).

Senene is a delicacy exported to Haya relatives living in distant places like UK or to wedding ceremonies held as far as Dar es Salaam, 1500 km from Bukoba. 'Haya wedding ceremony will not be perfect until guests are welcomed by a pack of this delicacy at the entrance', said a respondent. According to Haya traditions, a reception with a plate of senene is a symbol of respect and acceptance to that family. Senene remains a protected snack, not to be offered to any person but few esteemed individuals.

Eating raw senene was reported to be a prohibited act; $92 \%$ of respondents had never eaten raw senene. Eating them raw was regarded unethical by most respondents who associate it with stomachache (52\%) and diarrhoea (48\%). There is scientific evidence that raw insects contain higher microbial counts, thus consuming them raw can bring such complications [20]. The remaining $8 \%$ had eaten fresh raw senene out of greed, although some apparently appreciated the raw senene. A young male respondent said 'senene are just so delicious even when freshly raw'. Senene are used in preparation of snacks, rat bait, chicken and fish feed; birds and monkeys are also reported to be consuming this important haya's delicacy.

Respondents reported that as it is with many African taboos, women and children had limitations towards senene consumption. Pregnant women were prohibited from eating senene or they would give birth to children with coned-head like that of senene. It was further believed that giving senene to infants and young children would make them unable to speak for the rest of their lives. This taboo is similar to that of the grasshopper clan of the Baganda in Uganda where women are prohibited to eat senene though they are allowed to catch them and cook for their husbands [13, 21]. However, several key informants questioned the taboo, suggesting the taboo was due to men's selfishness and desire to have all senene made for them. No medicinal beliefs were reported though senene are thought to be an aphrodisiac. There was a widespread belief that marriages became stronger and happier during senene season as women proudly collected and prepared them for their husbands, and, in return, they receive gifts such as kitenge, an esteemed traditional piece of cloth. Senene appendages, ovipositor and wings are not generally consumed and are discarded far from the main house across the road junction, as a show off to neighbours. Key informants explained the basis of this belief was to avoid the rotten smell, and prevent ants and flies from disturbing them in the house.

Although studies report protein rich arthropods, such as shellfish (mainly shrimp, lobster and crayfish) to be widely known for their ability to induce allergic reactions $[22,23]$, respondents reported no allergy caused by consumption of senene. Few respondents (28\%) reported diarrhoea cases after consuming excessive amount of senene; probably due to the high fat content and poor hygienic practices during processing. 


\section{Collection and harvesting}

The findings of this study suggested that traditionally, harvesting of fresh raw senene for family consumption was done through wild collection in fields. However, nowadays, it is common to harvest senene at home under very bright light since senene are nocturnal. Homestead collections were normally done by women and children of school age early in the morning before sunrise when they are inactive and hence easily captured. Commercialization of senene has triggered advancement in harvesting technology, using locally made traps (Figs. 2c and 3). The traps were made using folded iron sheets, large buckets and three very bright light bulbs (400 W each) as shown in Fig. 3.

The iron sheets were folded to a cone shape leading to the large bucket, which collected the falling senene (Fig. 2b). During the night, smoke was set under the bright light, which confused the senene hampering their ability to fly. A key informant reported that "Like a cow moving its head to the abattoir unsuspectingly, senene followed the bright light and dropped on folded iron sheets which slid them directly to the large bucket where they could not move out". When the buckets were full, trapped senene were transferred to big sisal sacks or bags and the traps reset ready for the next harvest until the swarm stopped, usually around 5 am during high seasons. Senene collectors reported that during high seasons normally eight to ten sacks (one sack approximately100 kg capacity) were collected on a single night swarm.

The majority of the respondents reported that they obtain senene for their consumption from market purchase (43\%) while others from wild collection (31\%), from setting traps (18\%) and as a gift from relatives $(8 \%)$.

\section{Processing methods}

From observations and responses from respondents, different processing methods have been grouped and discussed in different stages as shown in Figs. 4 and 5.

Edible insects processing is a common practice in almost all areas where they are consumed [24, 25]. Traditional processing methods are mostly similar among insect-consuming societies in Africa with slight differences between the processes. Processing is normally done for value addition to increase palatability, safety and for preservation purpose. Processing ensures removal/reduction of anti-nutrients such as phytates and tannins [26]. Processing methods significantly impact the nutritional value of the insects [10].

\section{Cleaning and washing of fresh raw senene after harvest}

Cleaning was done to remove inedible body parts namely wings, appendages and ovipositor for female senene (Fig. 4). Wood ashes are used to increase friction and ease the process. Antennae, which are slippery and light, were often not removed as they disappeared within processing chain. At this stage, other insects collected with the senene as well as grasses and other waste materials are removed. Some reported washing with cold water before further processing; however, some did not wash claiming that washing would drain out fat and make senene less enjoyable.

\section{Boiling}

Cleaned and/or washed senene were placed in boiling salted water with or without spices (such as onions, garlic, ginger and cardamom) and then left to boil for about 15 min (Fig. 5). This is normally a stage in making smoked, toasted and deep fried senene. However, boiled senene can also be eaten, either drained out or consumed with the stock. The soup (liquid part without senene) is sometimes mixed with boiled banana and given to children by some of the locals (10\%).

\section{Smoking}

This was reported to be a traditional method of processing senene. Results showed that $21 \%$ of senene consumer preferred smoked senene above other processing methods, especially older people (51-60 years) (Fig. 7). The smoky aroma of smoked senene and its antique was among the mentioned reasons for its acceptance. Fresh raw or boiled senene are rolled in fresh banana leaves then placed on the kitchen roof (obutala in Haya language). Others used a

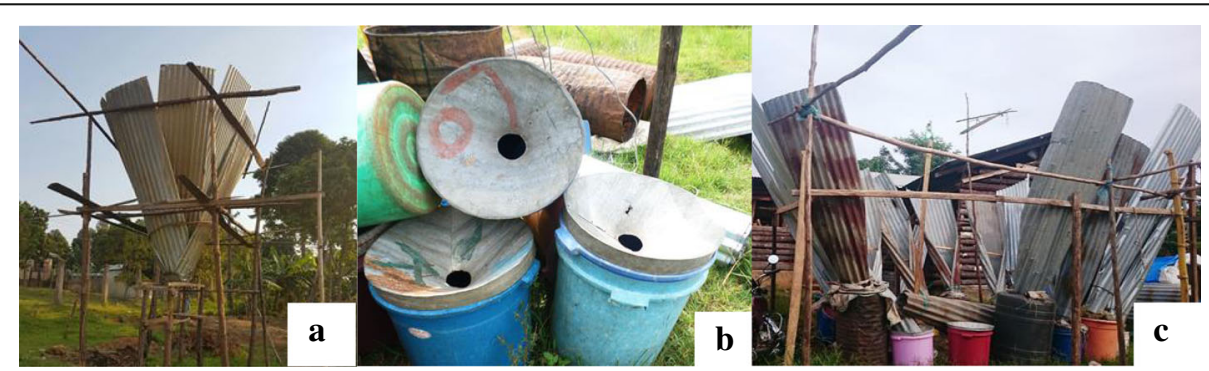

Fig. 2 Senene harvesting using traditionally made traps. a Corrugated iron sheets folded into a cone shape and held in position using props. b Large buckets with a hole on the lid. c An assembled trap ready for harvesting 


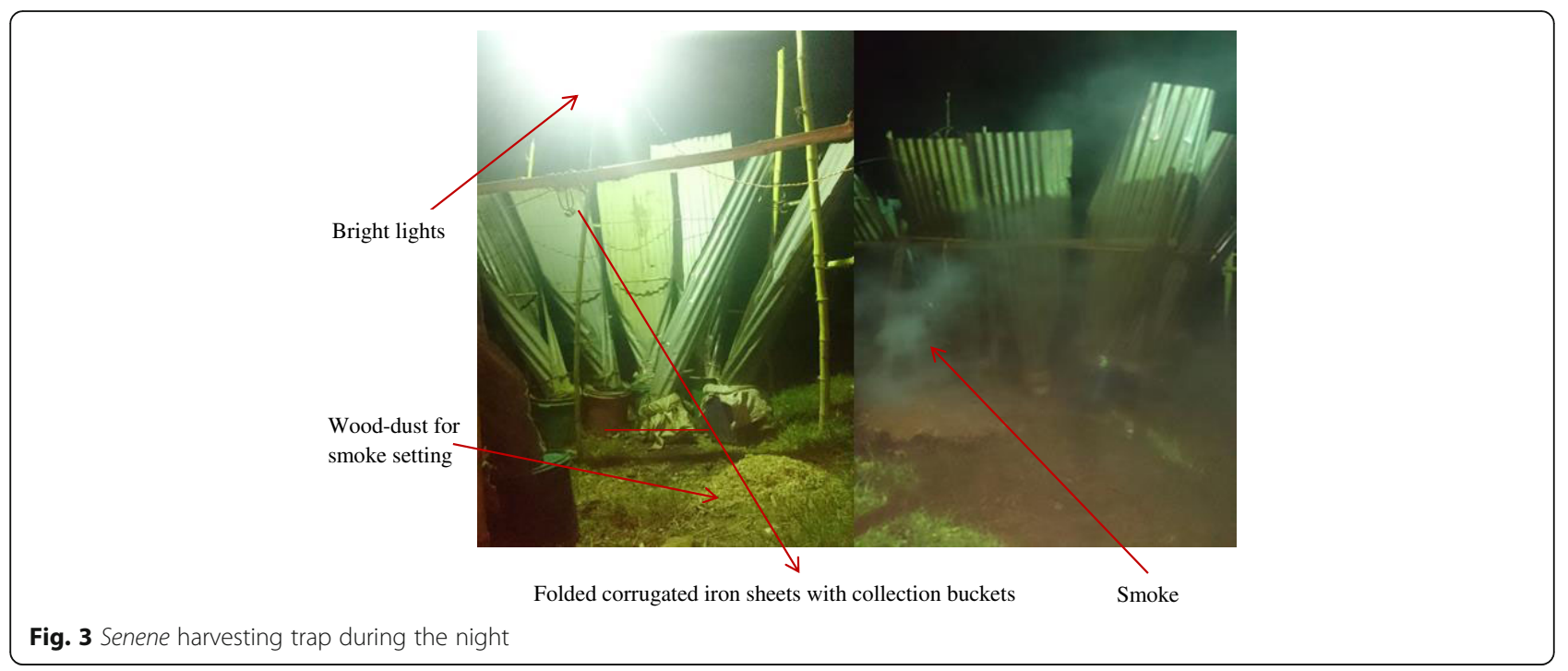

special roof extension for senene placed along the direction of smoke from the burning firewood known as akashelo (Fig. 6b). Smoking was explained to follow two similar processing lines as shown in Figs. 4 and 5. Boiling was reported to be a mandatory step for short-time (2-4 days) smoked senene; it was optional where senene were to be smoked for a longer period. Ekyangwe was the name for special leaves burned together with firewood for senene smoking. The firewood used for senene smoking were those from trees characterised with slight or no smell, thus preventing alteration of senene's natural flavour.'You don't just smoke senene because there is smoke' said a key informant when asked about the type of trees used for senene smoking. Eucalyptus, cassava stems (Manihot esculenta), umbrella tree (Maesopsis eminii) and traditional trees such as msila were reported to have the best firewood for senene smoking.

\section{Toasting}

As summarised in Fig. 5, toasting is done by placing fresh raw or boiled senene in a hot pan, stirring them until they turned brown with a meat-like smell. Toasting was among the oldest methods still being practiced. Toasted senene became crunchy with less oil; thus, one could eat plentiful amounts before satiated. Toasted senene are brownish in colour (Fig. 6c). In urban areas, where the technology is available, baking ovens are used to toast senene.

\section{Deep frying}

Deep frying is currently the most $(22 \%)$ used and preferred processing method of processing senene by younger people (Fig. 7). Cleaned boiled or fresh raw senene were placed in boiling cooking oil (cottonseed oil was common) for about $10 \mathrm{~min}$ until they turned deepbrownish (Fig. 6d). The simplicity of this method has made it common and most liked among senene traders.

\section{Sun drying}

Sun drying was mainly for preserving senene for future processing, followed by storage in sisal sacks or plastic buckets. Senene became ready for consumption within 2 days of sun drying. The process took place on a locally made mat known as ebigara in Haya language (Fig. 6a).

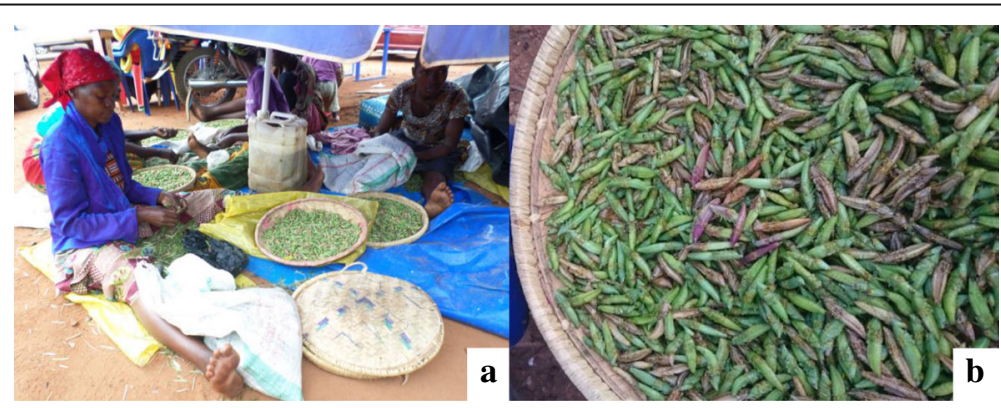

Fig. 4 a Senene cleaning and sorting at Bukoba town senene market. b Cleaned senene ready for sale 


\section{Fresh-raw Senene}

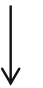

Removing appendages, wings, ovipositor, accompanying insects and dirt<smiles>[Tl]</smiles>

Washing using clean cold water

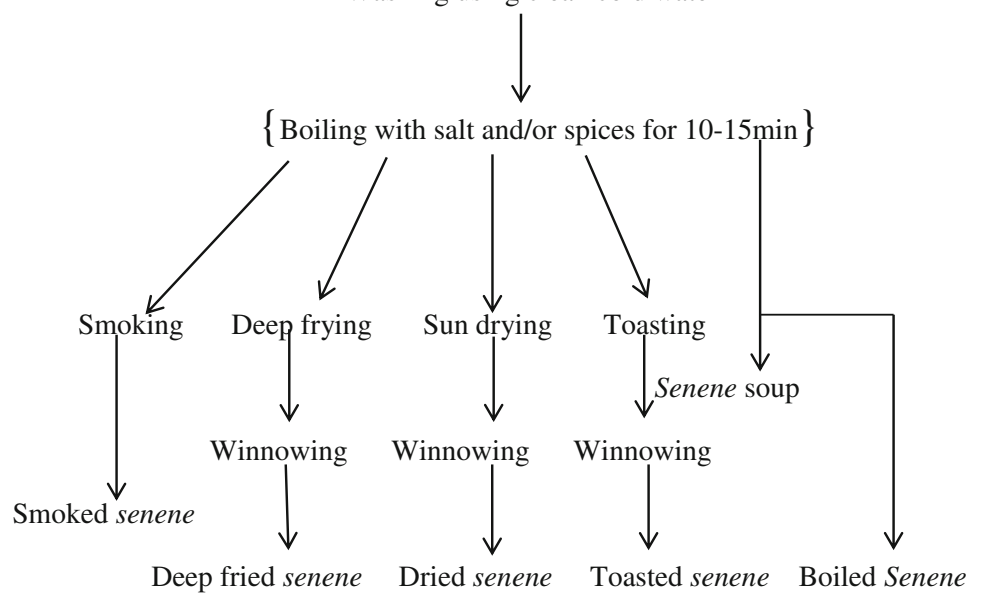

Fig. 5 Fresh senene processing flow diagram
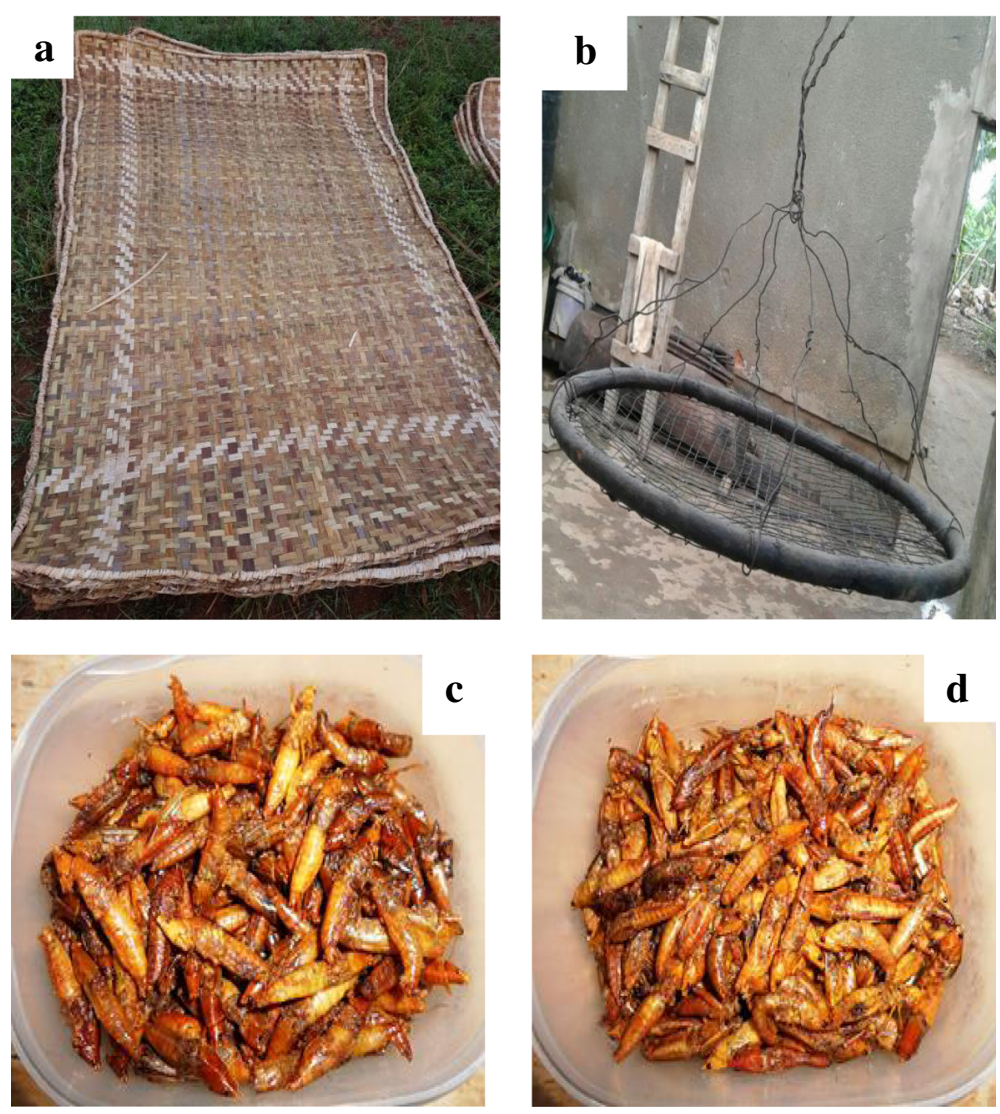

Fig. 6 a Ebigara. b Okashelo. c Deep fried senene. d Toasted senene 


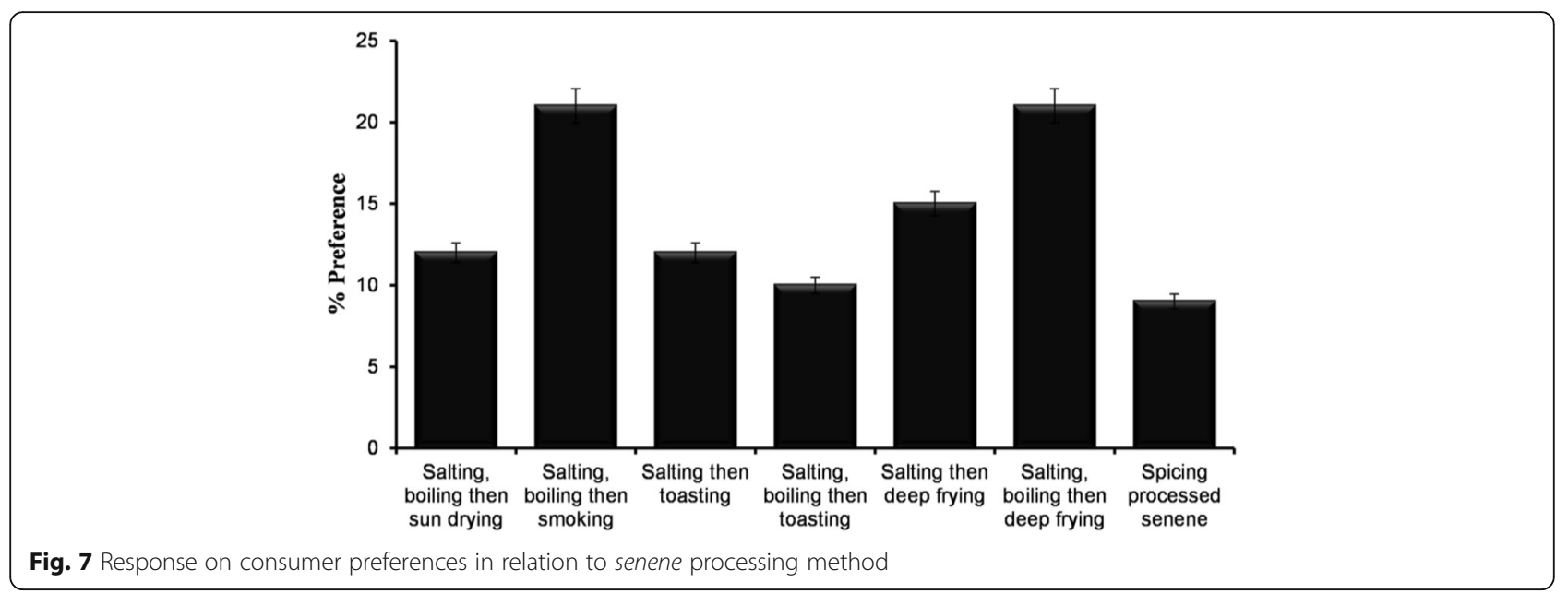

\section{Preservation and shelf-life}

Fresh senene have a very short shelf-life of about 12 to $48 \mathrm{~h}$ at room temperature of $24-28{ }^{\circ} \mathrm{C}$. Fresh raw senene were normally stored in polyethylene, sisal bags or mesh cloth bags that allow air to pass through. Senene traders normally used polyethylene bags to transport fresh senene; some spread senene on a mat temporarily before further processing. For a longer shelf-life, fresh senene are preserved using several traditional techniques such as smoking above the cooking place $(44 \%)$ and sun drying (Fig. 8). Nowadays, re-frying is common (41\%), and deep freezers and refrigerators are also used for storage and preservation. The average reported shelf-life for traditionally preserved senene is 12 months.

\section{Potential of senene in addressing child malnutrition}

Use of $R$. differens in enriching currently used complementary foods in this region, namely boiled banana (32\%) and cereal porridge (52\%), can make a considerable

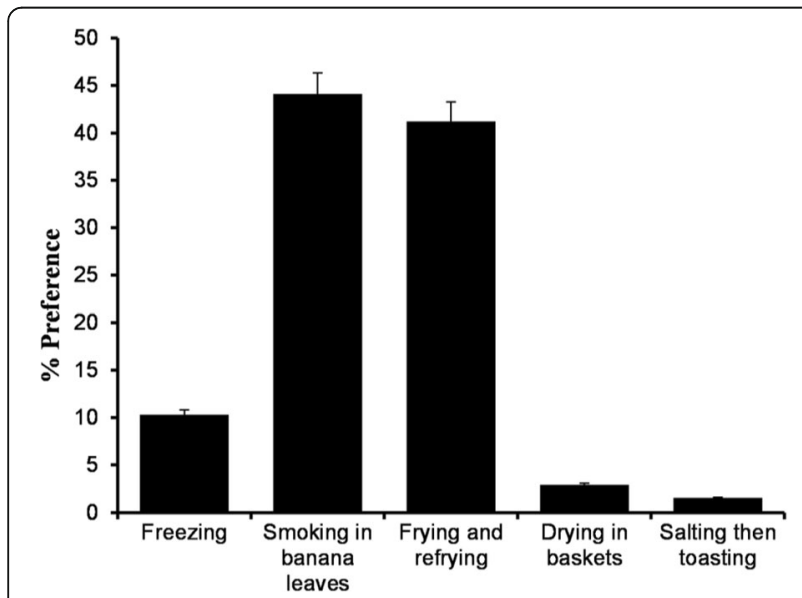

Fig. 8 Response on consumer preferences in relation to senene preservation methods contribution in reducing stunting rates. The Kagera region is named among the three regions exceeding the WHO $40 \%$ threshold of severe stunting [27]. Apart from the associated taboos towards withholding senene from children, the majority of the respondents reacted positively on the issue of including it in the infants' and children's diets. Table 1 presents respondents' feelings and suggestions concerning giving children senene.

The use of edible insects in addressing malnutrition has been evaluated by several researchers [28-34]. Silkworm pupae were included among essential ingredients for supplementary food to malnourished children in Congo [31]. Edible insects have also been utilised to enrich plantbased complementary foods. In Kenya, winged termites were used to enrich amaranth-based complementary foods [32] while in Cambodia, edible spiders were utilised to enrich a rice-based complementary food [28].

\section{Senene trade}

In Kagera region, senene trade was carried out by both men and women, with men dominating the commercial collection end while women were responsible for cleaning and processing (Fig. 4). Trade starts within the Kagera region among Hayas as $43 \%$ of respondents reported to obtain their senene from local traders. Both processed (mostly deep fried) in some cases, fresh raw senene were largely sold in this market (Fig. 9). Deep fried senene were transported throughout Tanzania; Dar es Salaam is the main destination. The price of fresh senene during the season averaged Tsh 1534.88 per kilogram while that of deep fried senene averaged Tsh 4254.05 per kilogram. Smoked, sundried and toasted types were not commonly found at the market place. The price of processed senene was more than twice that of fresh senene mainly due to tedious and laborious process of removing wings, appendages and ovipositor. Senene business is widely carried out from hawkers 
Table 1 Responses on feeding children with Senene

\begin{tabular}{|c|c|}
\hline Information collected & Percentage respondents (\%) \\
\hline \multicolumn{2}{|l|}{ Population currently giving senene to children $(n=51)$} \\
\hline Yes & 76.0 \\
\hline No & 24.0 \\
\hline \multicolumn{2}{|l|}{ Reasons for feeding children senene $(n=43)$} \\
\hline Are nutritious & 65.1 \\
\hline Children like senene & 27.9 \\
\hline I just feed them & 7.0 \\
\hline \multicolumn{2}{|l|}{ Reasons for not feeding children senene $(n=18)$} \\
\hline They cannot digest senene & 11.1 \\
\hline They cannot chew & 33.3 \\
\hline They may choke and block air & 38.9 \\
\hline It is a taboo & 16.7 \\
\hline \multicolumn{2}{|l|}{ Readiness to give senene to children if well prepared $(n=51)$} \\
\hline Yes & 90.0 \\
\hline No & 10.0 \\
\hline \multicolumn{2}{|l|}{ Commonly consumed complementary foods $(n=59)$} \\
\hline Single cereal & 39.0 \\
\hline Mixed cereals & 13.6 \\
\hline Boiled banana & 32.2 \\
\hline Mixed cereals and legumes & 8.5 \\
\hline Eat what adults eat & 6.8 \\
\hline \multicolumn{2}{|l|}{ Opinions on using senene in complementary feeding $(n=116)$} \\
\hline It is a nutritious food & 63.8 \\
\hline They should be given only senene soup & 6.9 \\
\hline Senene should be ground and sieved for children to swallow & 13.8 \\
\hline More research to be done & 6.0 \\
\hline Heads should be removed before giving to children & 3.4 \\
\hline Not a good thing because children will not be able to talk & 2.6 \\
\hline It is an act of disrespect to give senene to children & 1.7 \\
\hline Children likes senene & 1.7 \\
\hline
\end{tabular}

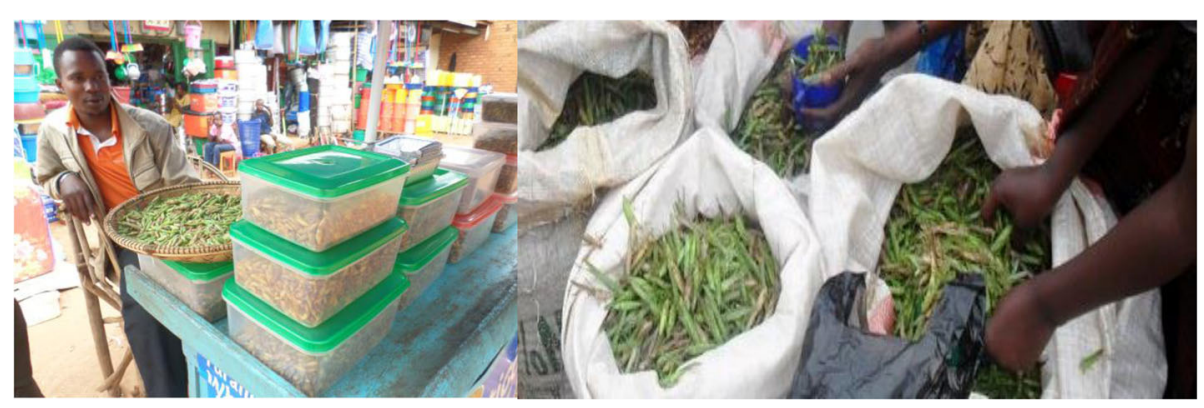

Fig. 9 Senene trade at Bukoba town senene market 
selling locally packed senene along the road side to big stores and supermarkets selling processed senene across Tanzania. Contribution to household income has not been reported, but most traders report that it covers almost half of their basic needs including school fees. Sixty one percent of respondents reported that one of the potential uses of senene is for income. There is potential for women employment as cleaning, and processing tasks are assigned to women, who are able to work to generate an income from senene production for about 3 months a year.

In Uganda, the grasshopper trade is characterised by wholesalers who buy grasshoppers from collectors and sell to retailers, who sell to consumers around Kampala [13]. The edible insects business is growing globally as the market for edible insects collected in the wild as well as reared in captivity increases [33]. For example, Belgium annually imports up to three tonnes and France five tonnes of dried mopane caterpillar from the Democratic Republic of Congo and Zambia [9, 29].

\section{Conclusion}

Our study shows that $R$. differens represents an important edible insect species for East African societies around the lake zone. Traditions, cultures and beliefs of different societies highly influence dietary choices and adoptions of new products. Understanding senene's ancient processing methods and indigenous technologies play a crucial role in innovations involving the food industry. Wild fields such as bushes and short grasses are important habitants for the life cycle of this seasonal delicacy. Maintenance of food habits and their values, in connection with urban migration, are main drivers of the increasing trade in edible insects across East Africa. Senene carries economic potential, essential for improving incomes and livelihoods of women and smallholder farmers. Senene can also be of use in enriching plantbased complementary foods for improved nutrition status of children.

\section{Recommendations}

As early as 1975 , edible insects were advocated as a food item to stave off malnutrition [3], but in order to get maximum benefit from senene as a food item, improvements to the indigenous processing technology are required to assure quality and safety of marketed senene. Promotion of senene as a delicious food among all consumers should be encouraged in order to tackle the challenges posed by limiting taboos. Inclusion of senene in the diets of infants and young children is a subject which requires attention of the researchers. Studies on environmental friendly ways to raise senene in captivity will increase the year round availability of this currently seasonal delicacy. Shelf-life studies on the senene processed by different methods are needed.
Abbreviations

DRC: Democratic Republic of Congo; SPSS: Statistical Package for Social Sciences

\section{Acknowledgements}

We gratefully acknowledge all Kagera district officials and natives who generously guided us and shared their knowledge. Special thanks to Dr. Katherine Pittore and J Ethnobiol Ethnomed reviewers and editors for their contributions in improving the manuscript.

\section{Funding}

The funding for the study was provided by USAID Innovative Agricultural Research Initiative (iAGRI) through Regional Universities Forum for Capacity Building in Agriculture (RUFORUM).

\section{Availability of data and materials}

The data that support the findings of this study are available from the authors upon reasonable request.

\section{Authors' contributions}

All authors are responsible for all parts of this paper. They all designed the study. MM conducted the field work and drafted the manuscript. HL, JK and JO contributed to the preparation and critical revision of the manuscript. All authors read and approved the final manuscript.

Ethics approval and consent to participate

Not applicable

\section{Consent for publication}

Informed written consent was obtained from senene harvesters, traders and respondents for publication of information and accompanying images.

\section{Competing interests}

The authors declare that they have no competing interests.

\section{Publisher's Note}

Springer Nature remains neutral with regard to jurisdictional claims in published maps and institutional affiliations.

\author{
Author details \\ ${ }^{1}$ Department of Food Science and Technology, Jomo Kenyatta University of \\ Agriculture and Technology, P. O. Box 62000-00200, Nairobi, Kenya. \\ ${ }^{2}$ Department of Food Technology, Nutrition and Consumer Sciences, \\ Sokoine University of Agriculture, P.O. Box 3006, Chuo Kikuu, Morogoro, \\ Tanzania.
}

Received: 11 March 2017 Accepted: 24 October 2017

Published online: 13 November 2017

References

1. Van Huis A. Potential of insects as food and feed in assuring food security. Annu Rev Entomol. 2013;58:563-83.

2. Ramos-elorduy J. Anthropo-entomophagy: cultures, evolution and sustainability. Entomol Res. 2009;39:271-88.

3. Meyer-rochow VB. The use of insects as human food. Food Nutr Notes Rev. 1976;33(4):151-3.

4. Meyer-Rochow VB. Ethno-entomological observations from North Korea (officially known as the Democratic People's Republic of Korea). J Ethnobiol Ethnomed. 2013:9:7.

5. Kinyuru J, Kenji GM, Muhoho SN. Nutritional potential of longhorn grasshopper (Ruspolia differens) consumed in Siaya District, Kenya. J Agr Sci Technol. 2010;12:32-46.

6. Moreki JC. A study of entomophagy in Mogonono in Kweneng District, Botswana. Online Int Interdiscip Res J. 2014;4(IV):70-9.

7. Chakravorty J, Ghosh S, Jung C, Meyer-rochow VB. Nutritional composition of Chondacris rosea and Brachytrupes orientalis: two common insects used as food by tribes of Arunachal Pradesh, India. J Asia Pac Entomol. 2014;17(3):407-15.

8. Jongema Y. List of edible insects of the world. Wageningen: Wageningen UR; 2015. p. 1-75. 
9. Bailey WJ, Mccrae AWR. The general biology and phenology of swarming in the East African tettigoniid Ruspolia differens (Serville) (Orthoptera). J Nat Hist. 1978;12(3):259-88.

10. Kinyuru JN, Kenji GM, Njoroge S. Effect of processing methods on the in vitro protein digestibility and vitamin content of edible winged termite (Macrotermes subhylanus) and grasshopper (Ruspolia differens). J Food Bioprocess Technol. 2010;3:778-82.

11. Siulapwa N, Mwambungu A, Lungu E, Sichilima W. Nutritional value of four common edible insects in Zambia. Int J Sci Res. 2014;3(6):876-84.

12. Matojo ND, Njau MA. Plasticity and biosystematics of swarming of the conehead Ruspolia differens Serville (Orthoptera: Conocephalidae). Int J Intergrative Biol. 2010;9(2):97-103.

13. Agea JG, Biryomumaisho M, Buyinza NG. Commercialization of R. nitidula (nsenene grasshoppers) in central Uganda. Afr J Food Agr Nutr Dev. 2008;8(3):319-32.

14. Bailey WJ, Robinson D. Song as a possible isolating mechanism in the genus Homorocoryphus (Tettigonioidea, Orthoptera). Anim Behav. 1971;19:390-7.

15. Matojo ND, Hosea KM. Phylogenetic relationship of the longhorn grasshopper Ruspolia differens Serville (Orthoptera: Tettigoniidae) from Northwest Tanzania based on 18S ribosomal nuclear sequences. J Insects. 2013:2013:1-5.

16. Ramos-Elorduy J. Threatened edible insects in Hidalgo, Mexico and some measures to preserve them. J Ethnobiol Ethnomed. 2006;51(2):1-10.

17. Rumpold BA, Schl OK. Nutritional composition and safety aspects. J Mol Nutr Food Res. 2013:57:802-23.

18. Tanzania National Bureau of Statistics - Ministry of Finance Office of Chief Government Statistician President's Office - Finance, Economy and Development Planning.United Republic of Tanzania. Migration and urbanisation report: 2012 population and housing census. Dar es Salaam; 2015.

19. Matojo ND, Yarro JG. Variability in polymorphism and sex ratio of the conehead Ruspolia differens Serville (Orthoptera: Conocephalidae) in northwest Tanzania colour morphs. Int J Intergrative Biol. 2010;9(3):131-6.

20. Ssepuuya, Aringo RO, Mukisa IM, Nakimbugwe D. Effect of processing, packaging and storage-temperature based hurdles on the shelf stability of sautéed ready-to-eat Ruspolia nitidula. J Insects Food Feed. 2016;4(2):245-53.

21. Meyer-rochow VB. Food taboos: their origins and purposes. J Ethnobiol Ethnomed. 2009;5:8.

22. Barre, Caze-Subra S, Gironde C, Bienvenu F, Bienvenu J, Rougé P. Entomophagie et risque allergique. Revue Francaise d'Allergologie. 2014;54(4):315-21.

23. Ayuso, Sánchez-Garcia S, Pascal M, Lin J, Grishina G, Fu Z, Ibáñez MD, Sastre J, Sampson HA. Is epitope recognition of shrimp allergens useful to predict clinical reactivity. Clin Exp Allergy. 2012;42(2):293-304.

24. Meyer-Rochow VB, Nonaka K, Boulidam S. More feared than revered: insects and their impact on human societies (with some specific data on the importance of entomophagy in a Laotian Setting). Entomologie heute. 2008;20:3-25.

25. Defoliart GR. Insects as Food: why the Western attitude is important. Annu Rev Entomol. 1999;44(80):21-50.

26. Chukwunoso NE. The differences and nutritional status of edible insects in Nigeria. Afric J Insects. 2014;1(3):21-7.

27. Tanzania Demographic and Health Survey. National Bureau of Statistics Dar es Salaam, Tanzania. Calverton: ICF Macro; 2016. Dar es salaam

28. Skau JKH, Touch B, Chhoun C, Chea M, Unni US, Makurat J, Roos N. Effects of animal source food and micronutrient fortification in complementary food products on body composition, iron status, and linear growth: a randomized trial in Cambodia. Am J Clin Nutr. 2015;101(3):742-51.

29. Nadeau L, Nadeau I, Franklin F, Dunkel F. The potential for entomophagy to address undernutrition. Ecol Food Nutr. 2015;54(3):200-8.

30. Barennes $\mathrm{H}$, Phimmasane $\mathrm{M}$, and Rajaonarivo $\mathrm{C}$. Insect consumption to address undernutrition, a national survey on the prevalence of insect consumption among adults and vendors in Laos. PLoS ONE. 2015;10(8):e0136458.

31. Bauserman M, Lokangaka A, Kodondi K, Gado J, Viera AJ, Bentley ME, Bose C. Caterpillar cereal as a potential complementary feeding product for infants and young children: nutritional content and acceptability. J Maternal Child Nutr. 2015;11:214-20.

32. Kinyuru JN, Konyole SO, Kenji GM. Identification of traditional foods with public health potential for complementary feeding in Western Kenya. J Food Res. 2012;1(2):148-58.

33. van Huis A, Van Itterbeeck J, Klunder H, Mertens E, Halloran A, Muir G, Vantomme. Economics: cash income, enterprise development, markets and trade. In: Edible insects: future prospects for food and feed security. Rome: FAO; 2012. p. 131-9.

34. Chakravorty J, Ghosh S, Meyer-rochow VB. Practices of entomophagy and entomotherapy by members of the Nyishi and Galo tribes, two ethnic groups of the state of Arunachal Pradesh. J Ethnobiol Ethnomed. 2011;7(1):5.

\section{Submit your next manuscript to BioMed Central and we will help you at every step:}

- We accept pre-submission inquiries

- Our selector tool helps you to find the most relevant journal

- We provide round the clock customer support

- Convenient online submission

- Thorough peer review

- Inclusion in PubMed and all major indexing services

- Maximum visibility for your research

Submit your manuscript at www.biomedcentral.com/submit 